\title{
Economic Evaluation of Continuous Subcutaneous Insulin Infusion for Children with Diabetes-Part II
}

\author{
Elina Petkova ${ }^{1}$, Valentina Petkova ${ }^{1}$, Maia Konstantinova ${ }^{2}$, Guenka Petrova $^{1}$ \\ ${ }^{1}$ Department of Social Pharmacy, Faculty of Pharmacy, Medical University, Sofia, Bulgaria \\ ${ }^{2}$ Endocrinology Clinic, University Pediatric Hospital, Medical University, Sofia, Bulgaria \\ Email: guenka.petrova@gmail.com
}

Received September 4, 2013; revised September 28, 2013; accepted October 7, 2013

Copyright (C) 2013 Elina Petkova et al. This is an open access article distributed under the Creative Commons Attribution License, which permits unrestricted use, distribution, and reproduction in any medium, provided the original work is properly cited.

\begin{abstract}
The aim of this study is to assess long-term metabolic outcomes in children with diabetes mellitus and to compare the efficacy, feasibility and metabolic control expenses for treatment with continuous subcutaneous insulin infusion (CSII), compared to human insulin treatment. The study sample included 34 children aged 3 to 18 years with type 1 diabetes, 17 with continuous subcutaneous insulin infusion (CSII) therapy and 17 with standard treatment with human insulin. The study observed for the following variables: duration of the disease, diabetic control, HbA1c deviation scores; height and weight deviation and price of the treatment. Methods applied include meta-analyses in the published medical literature, pharmacoeconomic analysis and statistical analysis. From the 34 children with diabetes type 1 observed retrospectively during the period 1999-2012, 17 were on CSII (mean age 10 years, mean duration of the disease -7 years, average usage of CSII-3 years). The test stripes cost 533 Euro/year (1100 stripes per year) and their average cost according to the duration of the disease is 3779.45 Euro since diagnosis. The blood glucose monitoring system costs 20 Euro and for the duration of the disease-4.96 Euro per patient per year. The average improvement of HbA(1c) after the CSII introduction is 1.85 , while after the application of human insulin- 0.28 . The treatment with CSII leads to significant improvement in glycemic control compared to the treatment with human insulin. The reduced $\mathrm{HbA}(1 \mathrm{c})$ shows good diabetes management, from one point of view, and good quality of life-from another.
\end{abstract}

Keywords: Diabetes; CSII; Metabolic Control

\section{Introduction}

The exponential rise in the prevalence of diabetes can be associated with an increase in the long-term complications that associate with this disease. Type-1-diabetes (T1DM) patients treated with unmodified regular human insulin (RHI) rarely achieve their glycemic target and often suffer from postprandial hyperglycemic incidents, together with an increased risk of hypoglycemia in the post-absorptive period [1]. The pattern of diabetic complications is changing. Western Europe advanced retinal disease and end-stage renal failure are diminishing, while coronary heart disease has become a leading complication. Recent meta-analyses in the literature have been found to improve glycemic control with continuous subcutaneous insulin infusion (CSII) compared with multiple daily injections (MDI) of insulin for patients with diabetes mellitus. For example, in Australia, CSII is predominantly used in type-1-diabetes mellitus patient ${ }^{*}$ Competing Interests: the authors declare that they have no competing interests. populations [2]. Continuous subcutaneous insulin infusion (CSII) is considered an option for type- 1 diabetic patients unsatisfactorily controlled with multiple daily injections (MDI). Short-acting analogs are superior to regular human insulin in CSII. There is evidence supporting the advantages of short-acting analog-based CSII over MDI in type-1 diabetes. The reduction of glycated hemoglobin (hba1c) level with CSII was evident in trials enrolling patients with mean age greater than 10 years [3]. The main goals for managing children with type-1-diabetes mellitus include achieving normal blood sugar levels, minimizing hypoglycemic incidents, optimizing quality of life, and preventing or delaying long-term complications. Continuous subcutaneous insulin infusion (CSII) is a treatment option that can assist in achieving all of these goals in all ages of children [4]. European Union countries reimburse insulin therapy for individuals with health insurance, but for CSII reimbursement, a variety of approaches exist [5-7]. The objective of this study is to assess the cost of using CSII of insulin to treat children 
with type-1 diabetes in Bulgaria and to compare it with the changes in BMI and $\operatorname{HbA}(1 \mathrm{c})$. The study was performed from the perspective of the Bulgarian NHIF and patients. The main study question discussed is "will the use of CSII be cost-effective for the Bulgarian health care system?”

\section{Methods}

\subsection{Literature Review}

PubMed was searched using keywords CSII, type-1 diabetes, pediatric population and all articles analyzing the safety, efficacy, and cost-effectiveness of CSII usage and human insulin treatment in the pediatric population were selected. In total, 4 studies were selected and their objectives, methodologies, results and conclusions were compared [2,8-10].

\subsection{Type of the CSII Usage Study}

In order to perform the main aim of the study a combined retrospective and prospective analysis of children patient records after the introduction of CSII was performed based on the patients' records and observation. The main setting is Endocrinology Clinic of University pediatric hospital of the Medical University, Sofia. The study was reviewed and approved by the Ethics committee of the Science medical council of the Medical University in Sofia.

\subsection{Patient Screening}

A total of 34 children with type-1-diabetes were observed divided into two groups: with an active group using CSII and a control group using human insulin therapy. Thirty children in the country use CSII, and of these, 17 were included in the survey, after their parents signed informed-consent forms. The active group included all children who began using the CSII pumps during the period 2007-2011 when the data collection began. Also since 2010, all children were transferred to real time insulin pumps; therefore at the moment of observation, they all used the same type of pump from the same manufacturer. The control group was formed after reviewing patient records and random selection according to age, duration of diabetes, entrance BMI and HbA1c level. Their parents also signed informed-consent forms.

\subsection{Data Collection}

The duration of the observation was from 01.02.2012 to 31.08.2012 (7 months). During this period, the diabetes maintenance phase after CSII introduction was measured. Data for the selected children was collected on their demographics, age, gender, weight, duration of disease, therapeutic schema (CSII or analogue insulin treatment with a pen device) and HbA1c before the inclusion in the pump program, and at the end of the observation.

\subsection{Cost-Effectiveness Analysis}

For both groups of children, the health care resources used by them were recorded, namely insulin, pumps (1 for 4 years), consumables for pumps (6 - 10 sets and 6 10 reservoirs), strips ( $n=1100$ per patient per year), glucometers (1 for 5 years including sensor prices), GP and endocrinology visits, and hospitalization due to diabetes. Sensors were used from 7 to 10 days. Yearly costs of CSII, blood glucose monitoring systems, insulin therapy, and strips were calculated by multiplying the number of resources used by their prices. Prices of pumps and blood glucose monitoring systems were collected from the manufacturers' websites. To calculate the yearly pump costs, the prices were divided by 4 , which is recommended by the manufacturers as the period of use for initial users [11]. All other costs were taken from the Bulgarian NHIF tariff [12]. Costs are presented in Bulgarian leva (BGN). At the time, the exchange rate was 1 Euro: 1.95 BGN. The primary outcome observed was the change in $\mathrm{HbA}(1 \mathrm{c})$ before the pump introduction and at the end of the study. The secondary outcome observed was the BMI change during the same period. In this pilot study we did not include the hypoglycemia episodes due to lack of data for all children. Children were introduced to pumps in different time periods, and in order to calculate the corresponding decrease in the HbA1c level, the total decrease during the period was divided into the duration of the period when the particular child was using the pump. Finally the average decrease for both groups was calculated.

\subsection{Sensitivity Analysis}

To test the robustness of the results, a one-way sensitivity analysis was performed by consecutively varying the changes in the HbA1c within the standard deviation interval for both groups of patients with 0.05 .

\subsection{Statistical Processing}

Descriptive statistics were applied to the patient's characteristic and outcomes. A T-test analysis was also performed to test the statistical significance in the outcome changes.

\section{Results}

Subcutaneous insulin infusion (CSII) systems are not a standard treatment for the Bulgarian children. So they are of a limited usage and are not included in the Positive list for reimbursement.

\subsection{Analysis of Published Studies}

There are 4 studies in the literature that discuss the effi- 
cacy, safety and/or cost-effectiveness of CSII usage in the pediatric population-Table 1. The number of observed patients varied from 19 to 95 . All of these studies measured the decrease in $\mathrm{HbA1C}$, and some, in addition, focused on patients' demographic characteristics, glucose level, hypoglycemia, and quality of life. All of the studies conclude that CSII is safe and effective, leading to greater decreases in HbA1c levels, allowing for improved quality of life, decreased hypoglycemic events and improved child and parent adherence as shown in Table 1.

The published studies define the HbA1c level as the widely accepted measure of diabetes control in pediatric practice. Positive therapeutic results after CSII introduction that might lead to better long-term outcomes are observed.

\subsection{Results of the Study}

The University pediatric clinic has been introducing CSII on the request of the parents, with only 30 children having applied so far. From 1999 to 2011, 17 children with diabetes type-1 were observed (mean age 113.82 months in the active group and 112.41 in the control group). The duration of diabetes was a little lower in the control group-Table 2. The average improvement of HbA (1c) in the active group after the CSII introduction is 1.85, while after the application of human insulin- 0.28 (Table 2).

From the 34 children with diabetes type 1 observed retrospectively during the period 1999-2012 17 were on CSII (mean age 10 years, mean duration of the disease7 years, average usage of CSII-3 years). The test stripes costs 533 Euro/year (1100 stripes per year) and their average cost according to the duration of the disease is 3779.45 Euro since diagnosis. The blood glucose monitoring system costs 20 Euro and for the duration of the disease-4.96 Euro per patient per year. The CSII price is 3896 Euro and compared to the duration of usage it costs 1290 euro per patient per year. Adding and the cost of insulin and pumps consumables the total yearly cost per patient in the active group treated with CSII is 2735.79 Euro. The total yearly cost weighed with the duration of the disease for the passive group treated with human insulin is 930.39 Euro (Table 3).

Based on these calculations the cost-effectiveness ration for the active group is 1563.31 Euro and for the group on human insulin is 3322.82 Euro. Thus the investment in the therapy of children diabetes with continuous infusion of insulin with pumps is cost-effective in comparison with the therapy with human insulin because it costs less for unit of HbA1c level improvement.

The one way sensitive analysis shows that the CSII therapy remains cost-effective within the established therapeutic interval.

\section{Discussion}

Continuous subcutaneous insulin infusion (CSII) systems are of a limited usage because they are not reimbursed by the Health Insurance Fund in Bulgaria. No official criteria for CSII usage in child populations have been established and only parents with sufficiently high income are able to afford such a therapeutic approach. In this sense, evaluation of the cost-effectiveness of CSII usage is influenced by a number of factors, such as health insurance policy, parents' preferences, income and therapeutic standards. This study shows that the usage of CSII with child populations is an efficient therapy and confirms similar findings reported in the literature on improvements in terms of better metabolic control, reduced rates of complications and better quality of life [2,13].

The study also shows that the children using CSII manage to maintain stable and target HbA1c levels, which are preconditions for better diabetes management (UKPDS, DCCT). The studies of the CSII usage in child populations are very limited for comparing long-term results in detail, but bearing in mind the evidence for the adult population, it can be predicted that strict and reliable disease control for children will support their longterm survival.

One limitation of this study is the small patient sample due to the limited number of children on CSII in Bulgaria, but it includes more than $57 \%$ of all the CSII users in the country, which ensures reliable results for the whole group. The number of the patients is twice as high as Wilsons' study [8]. We did not calculate the cost-effectiveness of CSII pumps related to the second observed outcome-BMI, because an increase in children's weight as a result of their normal developmental growth was observed in the both groups.

The results from the study can be an evidence for the Bulgarian NHIF to include CSII within the reimbursement system. Strict criteria for appropriate selection of children must be developed, as well as cost controls in order to make the final decision. The reimbursement practice in some countries provides such evidence, as in Serbia, where insurance authorities are paying for consumables and patients' families are paying for pumps. In countries with high GDP, CSII is included within the scope of the reimbursement system [7].

\section{Conclusion}

The treatment with CSII leads to significant improvement in glycemic control compared to the treatment with human insulin. The reduced $\mathrm{HbA}(1 \mathrm{c})$ shows good diabetes management, from one point of view, and good quality of life-from another.

\section{Acknowledgements}

We wish to thank to the staff of University paediatric 
Table 1. Summary of the main findings from the published studies.

\begin{tabular}{|c|c|c|c|c|}
\hline Authors & Objective & Methodology & Results & Conclusions \\
\hline $\begin{array}{c}\text { Plotnick et al., } \\
2003\end{array}$ & $\begin{array}{l}\text { To evaluate the safety } \\
\text { and effectiveness of } \\
\text { insulin pump therapy in } \\
\text { children and adolescents } \\
\text { with type-1 diabetes. }\end{array}$ & $\begin{array}{l}\text { All patients who started } \\
\text { insulin pump therapy between } \\
1 \text { January } 1990 \text { and } 31 \\
\text { December } 2000 \text { were } \\
\text { included in this study. } \\
\text { HbA1c was measured at } \\
\text { each visit by cation-exchange } \\
\text { high-performance liquid } \\
\text { chromatography. }\end{array}$ & $\begin{array}{l}\text { There was a small but significant } \\
\text { decrease in HbA1c at } 3 \text { - } 6 \text { months } \\
\text { after starting with pump ( } 7.7 \text { vs. } \\
\text { 7.5\%; } P<0.03) \text {. HbA1c levels then } \\
\text { gradually increased and remained } \\
\text { elevated after } 1 \text { year of follow-up. } \\
\text { There were fewer hypoglycemic } \\
\text { events after pump start (12 vs. } 17 \text {, } \\
\text { rate ratio } 0.46,95 \% \text { CI } 0.21 \text { - } 1.01) \text {. }\end{array}$ & $\begin{array}{l}\text { Insulin pump use was safe and } \\
\text { effective. After adjusting for age } \\
\text { and duration of diabetes, HbA1c } \\
\text { was in fact lower after pump } \\
\text { placement. Both monitoring } \\
\text { frequency and parental } \\
\text { involvement were significantly } \\
\text { associated with lower } \\
\text { HbA1c levels. }\end{array}$ \\
\hline $\begin{array}{c}\text { Bode et. al, } \\
2002\end{array}$ & $\begin{array}{l}\text { To compare multiple } \\
\text { daily injections (MDI), } \\
\text { and CSII and to assess } \\
\text { the effects on quality } \\
\text { of life. }\end{array}$ & Comparative analysis & $\begin{array}{l}\text { The effectiveness of CSII } \\
\text { and improvements in pump } \\
\text { technology have fueled a dramatic } \\
\text { increase in the use of this therapy. }\end{array}$ & $\begin{array}{l}\text { Insulin pump or continuous } \\
\text { subcutaneous insulin infusion } \\
\text { (CSII) therapy provides a treatment } \\
\text { option that can dramatically aid in } \\
\text { achieving all of these goals. }\end{array}$ \\
\hline $\begin{array}{l}\text { Cohen et al., } \\
\qquad 2007\end{array}$ & $\begin{array}{l}\text { To project long-term } \\
\text { costs and outcomes of } \\
\text { CSII compared with } \\
\text { MDI in adult and } \\
\text { adolescent T1DM. }\end{array}$ & $\begin{array}{l}\text { The study modeled analysis } \\
\text { utilizing a lifetime horizon } \\
\text { in adult and adolescent } \\
\text { specialty-care type-1-diabetes } \\
\text { patient populations from } \\
\text { Australia. }\end{array}$ & $\begin{array}{l}\text { Treatment with CSII is associated } \\
\text { with an improvement in life } \\
\text { expectancy of } 0.393 \text { years for } \\
\text { adults compared with MDI and } \\
0.537 \text { years for adolescents. The } \\
\text { corresponding gains in QALYs } \\
\text { were 0.467 QALYs and 0.560 } \\
\text { QALYs for adults and adolescents, } \\
\text { respectively. This produced } \\
\text { incremental cost effectiveness } \\
\text { ratios (ICERs) of \$A88220 and \$A } \\
\text { 77851 per life-year gained for CSII } \\
\text { compared with MDI for adult and } \\
\text { adolescent T1DM. }\end{array}$ & $\begin{array}{l}\text { The analysis suggests that CSII } \\
\text { is associated with ICERs in the } \\
\text { range of \$A53022 - } 259646 \text { per } \\
\text { QALY gained with most ICERs } \\
\text { representing a significant savings } \\
\text { in Australia under the majority } \\
\text { of scenarios explored. }\end{array}$ \\
\hline
\end{tabular}

Table 2. Patient demographic.

\begin{tabular}{|c|c|c|c|c|c|}
\hline & Gender & Age months & $\operatorname{HbA}(1 c) 1$ & HbA(1c) 2 & Months with diabetes \\
\hline Pumps & $1.41 \pm 0.5$ & $113.82 \pm 49.0$ & $8.79 \pm 0.88$ & $6.94 \pm 0.65$ & $66.65 \pm 41.07$ \\
\hline $\mathrm{HI}$ & $1.47 \pm 0.1$ & $108.65 \pm 10.2$ & $10.68 \pm 0.2$ & $10.40 \pm 0.3$ & $22.76 \pm 2.92$ \\
\hline
\end{tabular}

Table 3. Yearly cost of therapy in both groups.

\begin{tabular}{cccccc}
\hline & Insulin cost & Pump cost & Pen cost & Consum. & Stripes \\
\hline Pumps & $37.83 \pm 12.00$ & 1290.0 & - & 870.00 & 533.00 \\
Human Insulin & $17.43 \pm 1.68$ & & 150 & 225.00 & 533.00 \\
\hline
\end{tabular}

clinic for their contribution to this project; and for their valuable technical support and for their help in collecting the data.

\section{REFERENCES}

[1] A. Mosca, A. Lapolla and P. Gillery, “Glycemic Control in the Clinical Management of Diabetic Patients," Clinical Chemistry and Laboratory Medicine, Vol. 51, No. 4, 2013, pp. 753-766. http://dx.doi.org/10.1515/cclm-2012-0594

[2] N. Cohen, M. E. Minshall, L. Sharon-Nash, K. Zakrzewska, W. J. Valentine and A. J. Palmer, "Continuous Subcutaneous Insulin Infusion versus Multiple Daily Injections of Insulin: Economic Comparison in Adult and Ado- 
lescent Type 1 Diabetes Mellitus in Australia,” Pharmacoeconomics. Vol. 25, No. 10, 2007, pp. 881-897. http://dx.doi.org/10.2165/00019053-200725100-00006

[3] M. Monami, C. Lamanna, N. Marchionni and E. Mannucci, "Continuous Subcutaneous Insulin Infusion versus Multiple Dailyinsulin Injections in Type 1 Diabetes: A MetaAnalysis,” Acta Diabetologica, Vol. 47, No. 1, 2010, pp. 77-81. http://dx.doi.org/10.1007/s00592-009-0132-5

[4] W. Tamborlane, K. Swan, K. Sikes, A. Steffen and S. Weinzimer, "The Renaissance of Insulin Pump Treatment in Childhood Type 1 Diabetes," Reviews in Endocrine \& Metabolic Disorders, Vol. 7, No. 3, 2006, pp. 205-213. http://dx.doi.org/10.1007/s11154-006-9018-9

[5] G. Soltesz, C. C. Patterson and G. Dalquist, "EURODIAB Study Group Worldwide Childhood Type 1 Diabetes Incidence-What Can We Learn from Epidemiology?” Pediatric Diabetes, Vol. 8, Suppl. 6, 2007, pp. 6-14. http://dx.doi.org/10.1111/j.1399-5448.2007.00280.x

[6] F. Carle, R. Gesuita, G. Bruno, G. V. Coppa, A. Falorni, R. Lorini, et al., "Diabetes Incidence in 0- to 14-Year Age-Group in Italy,” Diabetes Care, Vol. 27, No. 12, 2004, pp. 2790-2796. http://dx.doi.org/10.2337/diacare.27.12.2790

[7] G Stipancic, L. La Grasta Sabolic, M. Sepec, A. Radica, V. Skrabic, S. Severinski and M. Tiljak, "Regional Differences in Incidence and Clinical Presentation of Type 1
Diabetes in Children Aged under 15 Years in Croatia," Croatian Medical Journal, Vol. 53, No. 2, 2012, pp. 141148. http://dx.doi.org/10.3325/cmj.2012.53.141

[8] L. Plotnik, et al., "Safety and Effectiveness of Insulin Pump Therapy in Children and Adolescents with Type 1 Diabetes,” Diabetes Care, Vol. 26, No. 4, 2003, pp. 11421146. http://dx.doi.org/10.2337/diacare.26.4.1142

[9] B. W. Bode, H. T. Sabbah, T. M. Gross, L. P. Fredrickson and P. C. Davidson, "Diabetes Management in the New Millennium Using Insulin Pump Therapy,” Diabetes/ Metabolism Research and Reviews, Vol. 18, No. S1, 2002, pp. S14-S20. http://dx.doi.org/10.1002/dmrr.205

[10] D. Wilson, et al., “A Two-Center Randomized Controlled Feasibility Trial of Insulin Pump Therapy in Young Children with Diabetes,” Diabetes Care, Vol. 28, No. 1, 2005, pp. 15-19. http://dx.doi.org/10.2337/diacare.28.1.15

[11] http://www.medtronic-diabetes.bg/

[12] http://www.nhif.bg

[13] O. Cohen, A. Korner, R. Chlup, C. S. Zoupas, A. K. Ragozin, K. Wudi, et al., "Improved Glycemic Control through Continuous Glucosesensor-Augmented Insulin Pump Therapy: Prospective Results from a Community and Academic Practice Patient Registry," Journal of Diabetes Science and Technology, Vol. 3, No. 4, 2009, pp. 804-811. 